Annuaire suisse de politique de développement

22-2 | 2003

Société de l'information et coopération internationale

\title{
Pas sans nos langues
}

Alpha Oumar Konaré

\section{OpenEdition}

\section{Journals}

Édition électronique

URL : http://journals.openedition.org/aspd/499

DOI : 10.4000/aspd.499

ISSN : 1663-9669

Éditeur

Institut de hautes études internationales et du développement

Édition imprimée

Date de publication : 1 novembre 2003

Pagination : XI

ISSN : 1660-5934

\section{Référence électronique}

Alpha Oumar Konaré, «Pas sans nos langues », Annuaire suisse de politique de développement [En ligne], 22-2 | 2003, mis en ligne le 16 mars 2010, consulté le 24 septembre 2020. URL : http:// journals.openedition.org/aspd/499; DOI : https://doi.org/10.4000/aspd.499 


\section{Pas sans nos langues}

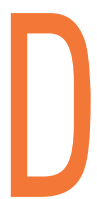

epuis plus d'une décennie, les Africains se sont engagés dans une nouvelle conquête, mettre les technologies de l'information au service de leur développement. Cet engagement se justifie par la conviction que ces nouveaux outils sont profitables au plus grand nombre. Si Internet était seulement d'usage personnel, il aurait un faible intérêt pour nous, populations des pays du Sud. Ces technologies n'ont de sens que s'il existe la possibilité d'une appropriation collective.

Ces technologies doivent d'abord aider les Africains dans leur combat pour le développement et l'intégration régionale, pour la consolidation du processus démocratique (bonne gouvernance, transparence, Etat de droit), en faisant la promotion des grandes langues africaines porteuses de savoirs et de cultures. Les savoirs et les valeurs qui ont bâti nos civilisations sont notre force et ne peuvent être communiqués qu'à travers nos langues. A l'heure de la construction d'un savoir mondial se dresse naturellement la question des rapports de force entre les différentes cultures du monde, par le biais notamment de leur présence sur Internet. Au moment des grandes ouvertures, l'Afrique doit agir avec prudence pour ne pas lâcher ce qui lui reste, son patrimoine, qui demain pourra enrichir notablement le patrimoine de l'humanité.

L'espoir repose sur l'amélioration du dialogue Nord-Sud. L'Afrique est plus que jamais prête au changement et à une plus forte participation dans toutes les instances de décisions mondiales. Encore faut-il que le reste du monde y soit prêt et que celui-ci témoigne d'une solidarité profonde avec les populations du Sud.

Je salue donc cet ouvrage qui met en lumière les mécanismes de coopération internationale dans ce domaine prometteur que sont les technologies de l'information et de la communication et rappelle que leur extension ne prendra sens que si elles sont motivées par la création de contenus locaux. L'objectif fondamental est que les Africains se retrouvent eux-mêmes sur la toile mondiale autour de leurs valeurs partagées et qu'ensuite, ensemble, ils puissent transmettre le capital partagé au reste du monde. Nous ne succomberons pas aux contenus clés en main conçus à l'intention des peuples du Sud - de bonne foi ou pour des raisons mercantiles - pour ne pas risquer de favoriser la résurgence de vieux réflexes de colonisation culturelle et d'aliénation économique. La présence de contenus africains est la seule garantie du profit que nous pourrons tirer de la société de l'information en devenir.

Alpha Oumar KONARÉ

Ancien président de la République du Mali et président de l'Union africaine 